(C) 2019 by the Arizona Board of Regents on behalf of the University of Arizona

\title{
RADIOCARBON PRETREATMENT COMPARISONS OF BALD CYPRESS (TAXODIUM DISTICHUM) WOOD SAMPLES FROM A MASSIVE BURIED DEPOSIT ON THE GEORGIA COAST, USA - ERRATUM
}

Katharine G Napora • Alexander Cherkinsky • Robert J Speakman • Victor D Thompson • Robert Horan • Craig Jacobs

doi: 10.1017/RDC.2019.121, published by Cambridge University Press, 11 October 2019.

In the original publication of this article, an incorrect $x$-axis label was given for Figure 3. The correct Figure 3 follows on the next page.

The publisher apologizes for this error. 
Figure 3 Calibrated probability distributions for radiocarbon dates from 105 of the 107 bald cypress trees obtained at the Altamaha WMA. Two other bald cypress trees were shown to be modern in date. Some cookies were dated at both rings close to the pith $(>10$ rings from the pith) and outer rings, while other cookies were dated at only outer rings. Dates on individual trees are separated by horizontal dashed lines. Radiocarbon calibration was conducted employing OxCal 4.3.2 (Bronk Ramsey 2009) and the IntCal13 curve (Reimer et al. 2013), with ranges rounded off by 5 years. From OxCal v.4.3.2 online.

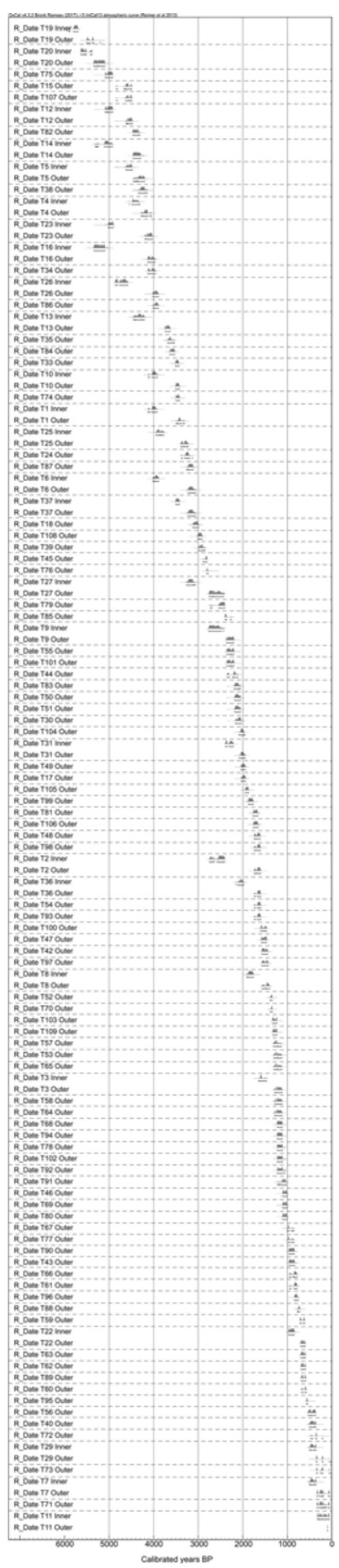




\section{REFERENCE}

Napora KG, Cherkinsky A, Speakman RJ, Thompson VD, Horan R, Jacobs C. 2019. Radiocarbon pretreatment comparisons of bald cypress (Taxodium distichum) wood samples from a massive buried deposit on the Georgia coast, USA. Radiocarbon:1-9. doi: $10.1017 /$ RDC.2019.121. 